\title{
Anti-Inflammatory Biologics and Anti-Tumoral Immune Therapies-Associated Colitis: A Focused Review of Literature
}

\author{
Weixun Zhou ${ }^{\mathrm{a}, \mathrm{e}}$, Yan Huang ${ }^{\mathrm{b}, \text { e }}$, Jinping Lai ${ }^{\mathrm{c}}$, Jun Lu ${ }^{\mathrm{d}}$, Michael Feely ${ }^{\mathrm{c}}$, Xiuli Liu ${ }^{\mathrm{c}}$,
}

\begin{abstract}
An increasing number of drugs including monoclonal antibodies and small molecules, either anti-inflammatory or immunity-enhancing, have been developed to treat human diseases and the number of medications in these classes is likely to expand in the future. The two most commonly used categories of such therapies are the anti-inflammatory group (anti- tumor necrosis factor (TNF) $\alpha$, anti-interleukins/ interleukin receptors, and anti-integrin bodies) and the anti-tumoral agents (immune checkpoint inhibitors, anti-CD20, and anti-endothelial growth factor). Although the anti-inflammatory biologics have brought about a revolutionary effect in the management of a variety of autoimmune disorders including rheumatologic diseases, inflammatory bowel disease, and inflammatory dermatological diseases, their ability to induce colitis in patients without a prior history of colitis or exacerbate quiescent colitis has been increasingly and unexpectedly recognized. While the use of immune-augmenting monoclonal antibody therapies results in a significant survival benefit in a subset of patients with malignancies, these monoclonal antibodies also have the ability to cause colitis through an apparent autoimmune mechanism. Colitis associated with these medications may demonstrate multiple histologic patterns including increased apoptosis (graft versus host disease (GVHD)-like), autoimmune enteropathy pattern, acute colitis pattern, ischemic colitis, inflammatory bowel disease pattern, either ulcerative colitis-like, Crohn's disease-like, or fulminant colitis-like. In addition, anti-inflammatory biologics are known to cause or reactivate latent infections such as tuberculosis and increase the risk for malignancies including high-grade lymphomas as well as indolent
\end{abstract}

Manuscript submitted May 6, 2018, accepted May 22, 2018

aDepartment of Pathology, Peking Union Medical College Hospital, Chinese Academy of Medical Sciences, Beijing, China

bepartment of Pathology, The Sixth Affiliated Hospital of Sun Yat-sen University, Guangzhou, Guangdong, China

'Department of Pathology, Immunology and Laboratory Medicine, College of Medicine, University of Florida, Gainesville, FL, USA

${ }^{\mathrm{d}}$ Department of Pathology, Beijing Chaoyang Hospital, Capital University, Beijing, China

${ }^{\mathrm{e} B}$ Both authors have contributed equally to this review.

${ }^{f}$ Corresponding Author: Xiuli Liu, Department of Pathology, Immunology and Laboratory Medicine, College of Medicine, University of Florida, Gainesville, FL 32610, USA. Email: xiuliliu@ufl.edu

doi: https://doi.org/10.14740/gr1041w lymphoproliferative disorders. Thus, the differential diagnosis for colitis in patients receiving therapeutic anti-inflammatory biologics or anti-tumoral agents can be broad. Optimal diagnosis and treatment requires a multidisciplinary approach. This review aims to provide an overview of the literature on the clinical features, histology, and treatment of these newly recognized anti-inflammatory biologic and anti-tumoral immune therapy-induced colitises and hopes this outlines will raise the vigilance of all clinicians of these entities.

Keywords: Anti-tumor necrosis factor- $\alpha$; Infliximab; Etanercept; Programmed cell death protein 1; Inflammatory bowel disease; Colitis; Crohn's disease; Ulcerative colitis

\section{Introduction}

More and more drugs including monoclonal antibodies, either anti-inflammatory or immunity-enhancing, are developed to treat human diseases and this list is expecting to expand in the future [1]. Two most commonly used categories are anti-inflammatory group (anti-tumor necrosis factor (TNF) $\alpha$, interleukins/interleukin receptors, and anti-integrin bodies) and anti-tumoral agents (immune checkpoint inhibitors, antiCD20, and anti-endothelial growth factor). Although anti-inflammatory biologics have brought about revolutionary effect in the management of a variety of autoimmune diseases including rheumatologic diseases, inflammatory bowel disease, and inflammatory dermatological diseases $[1,2]$, these therapeutic agents are increasingly and unexpectedly recognized to be able to induce colitis in patients without colitis prior to the initiation of this type of therapy or exacerbate quiescent colitis. Anti-inflammatory biologics-associated colitis is usually graded using a scale as previously proposed for medication/ drug-associated colitis based on clinical presentation and outcome (Table 1) [3] and has multiple histologic patterns including increasing apoptosis, autoimmune enteropathy pattern, acute colitis pattern, ischemic colitis, and inflammatory bowel disease (IBD) pattern, either ulcerative colitis (UC)-like, Crohn's disease (CD)-like, fulminant colitis-like, or ulcerative enterocolitis. In addition, anti-inflammatory monoclonal antibodies are known to cause or reactivate latent infections such as tuberculosis and increase risk for malignancies including 
Table 1. Grading Colitis-Associated With Medication/Drug

\begin{tabular}{lllll} 
& Grade 1 & Grade 2 & Grade 3 & Grade 4 \\
\hline Colitis & $\begin{array}{l}\text { Asymptomatic, } \\
\text { pathologic or radiographic } \\
\text { findings only }\end{array}$ & $\begin{array}{l}\text { Abdominal } \\
\text { pain; mucus or } \\
\text { blood in stool }\end{array}$ & $\begin{array}{l}\text { Abdominal pain; fever; } \\
\text { change in bowel habits with }\end{array}$ & $\begin{array}{l}\text { Life-threatening consequences (e.g. } \\
\text { ileum; perforation, bleeding, ischemia, }\end{array}$ \\
\end{tabular}

lymphoproliferative disorder. The use of immune-augmenting anti-tumoral antibodies results in significant survival benefit in a subset of patients with malignancies; these monoclonal antibodies are also known to induce the development of de novo colitis or flare-up of quiescent colitis. Thus, the differential diagnosis for colitis in patients receiving these therapeutic agents can be broad. The optimal diagnosis and treatment requires a multidisciplinary approach. This mini-review aims to review the literature on the clinical, histology, and treatment of colitis associated with the use of a few recently available and commonly used anti-inflammatory biologics and anti-tumoral immune therapies.

\section{Anti-Inflammatory Biologics}

TNF- $\alpha$ has been unequivocally validated as a therapeutic target in a variety of immune-mediated inflammatory disorders. Inhibition of the TNF- $\alpha$ pathway can be achieved by several methods and the currently available approaches include monoclonal antibodies (infliximab, adalimumab, and golimumab), either chimeric or humanized, a PEGylated Fab' fragment (certolizumab), and an IgG1-TNFR2 fusion protein (etanercept) [4]. These three anti-TNF- $\alpha$ subtypes differ with respect to Fc function, binding to a transmembrane precursor of TNF- $\alpha$ (tm TNF- $\alpha)$, and the ability to form complexes [4]. The properties of biologic TNF- $\alpha$ antagonists are summarized in Table 2 [4]. Although some of these agents, particularly anti-inflammatory antibodies, are approved to treat moderately to severely active IBD, either UC or CD $[1,2]$, they have been shown to cause colitis with multiple histologic patterns including increasing apoptosis, autoimmune enteropathy pattern, acute colitis pattern, ischemic colitis, and IBD pattern, either UC-like, CD-like, or fulminant colitis-like. Although there is a concern for perforation in patients receiving anti-TNF therapy, one study revealed that the risk of gastrointestinal perforations in patients with rheumatoid arthritis treated with anti-TNF therapy was not increased with an incidence rate of 24 - 53 per 100,000 person years [5].

\section{Anti-tumor necrosis factor- $\alpha$ (TNF- $\alpha)$ monoclonal antibodies}

\section{Infliximab}

Infliximab is a chimeric monoclonal antibody against TNF- $\alpha$. It has been widely used to treat a variety of chronic autoimmune diseases such as IBD, including moderate to severe UC and $\mathrm{CD}$, either with FDA approval or as an off-label use [4]. However, infliximab has been demonstrated to cause colitis.

1) IBD

Development of de novo UC was reported in one 55-year-old

Table 2. Anti-TNF- $\alpha$ Agents

\begin{tabular}{|c|c|c|c|c|c|c|c|}
\hline Drug name & $\begin{array}{l}\text { Registration } \\
\text { name }\end{array}$ & Structure & Ligands & $\begin{array}{l}\text { Molecular } \\
\text { weight (kDa) }\end{array}$ & $\begin{array}{l}\text { Half-life } \\
\text { (days) }\end{array}$ & Clinical use & $\begin{array}{l}\text { Other } \\
\text { features }\end{array}$ \\
\hline Infliximab & Remicade & Chimeric monoclonal antibody & $\begin{array}{l}\text { Soluble and } \\
\text { transmembrane } \\
\text { TNF- } \alpha\end{array}$ & 150 & $8-10$ & $\begin{array}{l}\text { CD, UC, RA, } \\
\text { AS, PA, PP }\end{array}$ & \\
\hline Adalimumab & Humira & Human monoclonal antibody & $\begin{array}{l}\text { Soluble and } \\
\text { transmembrane } \\
\text { TNF- } \alpha\end{array}$ & 150 & $10-20$ & $\begin{array}{l}\text { CD, RA, AS, } \\
\text { PA, PP, JIA }\end{array}$ & \\
\hline $\begin{array}{l}\text { Certolizumab } \\
\text { pegol }\end{array}$ & Cimzia & $\begin{array}{l}\text { TNF-specific, PEGylated } \\
\text { Fab' antibody fragment }\end{array}$ & $\begin{array}{l}\text { Soluble and } \\
\text { transmembrane } \\
\text { TNF- } \alpha\end{array}$ & About 95 & -14 & $\begin{array}{l}\text { RA, PA, } \\
\text { AS, CD }\end{array}$ & \\
\hline
\end{tabular}

AS: ankylosing spondylitis; CD: Crohn's disease; IBD: inflammatory bowel disease; JIA: juvenile idiopathic arthritis; PA: psoriatic arthritis; PP: plaque psoriasis; RA: rheumatoid arthritis; TNF: tumor necrosis factor; UC: ulcerative colitis. 
man with rheumatoid arthritis treated with infliximab [6]. The patient developed bloody diarrhea 2 weeks after his fourth infliximab infusion. Stool studies including assays for Clostridium difficile and cytomegalovirus were negative. Empirical treatment with metronidazole did not improve his diarrhea. Colonoscopy revealed moderately congested, erythematous, friable and granular mucosa in distal transverse colon, left colon, and the rectum. Biopsies from the colon demonstrated chronic active colitis with cryptitis, crypt abscess, crypt architectural distortion and dense lymphoplasmacytic infiltrates in the lamina propria, features of UC. Treatment for infliximabassociated UC includes cessation of the medication, addition of parental steroids, and/or leukocytapheresis $[6,7]$.

\section{2) Apoptotic enteropathy}

Many drugs are known to cause apoptotic enteropathy which is characterized by increased crypt epithelial apoptosis with or without crypt dropout. One case of apoptotic enteropathy was reported in a patient receiving infliximab [8]. The patient was treated with infliximab (400 mg every 4 weeks) for relapsing polychondritis associated with systemic vasculitis and chronic renal insufficiency. After 4 - 5 months, the patient developed watery diarrhea. Endoscopy only revealed a small ulcer in the sigmoid colon with the remaining colonic mucosa appearing otherwise unremarkable. Biopsies from the colon revealed architectural distortion, empty appearing lamina propria, cystically dilated crypts with atrophic epithelial lining and scattered apoptosis of basal crypt epithelium, features of apoptotic enteropathy. Biopsies of small bowel were not initially obtained in this case. The patient's diarrhea improved at 1 month following the last dose of infliximab. A repeat colonoscopy with biopsy revealed regenerative changes in the sigmoid colon. The remaining colonic mucosa showed improved but residual mild architectural distortion and an increased number of apoptotic cells in the crypt epithelium. Biopsies from the terminal ileum and duodenum were unremarkable while biopsies from the stomach showed a minimal increase in the number of apoptotic bodies.

\section{3) Ischemic colitis}

From the data submitted to United States (US) Food and Drug Administration's (FDA) Adverse Event Reporting System (AERS) between January 2003 and June 2011, 35 primary suspected reports of TNF- $\alpha$ inhibitors-associated ischemic colitis were identified from 155,372 cases. These patients' primary indication for therapy was rheumatoid arthritis and other potential causes of ischemic colitis were excluded including sepsis, serious cardiovascular conditions, coagulation disorders or chronic ischemic colitis [9]. Thirteen of these instances, including seven possible and six probable cases, were reported to be infliximab-associated ischemic colitis with a male to female ratio of 2:11 and median age of 68 years (range $55-83$ ). Eight cases were confirmed with colonoscopy with or without biopsy. Three patients died, nine patients recovered, and one was without follow-up data. Overall, the risk of ischemic

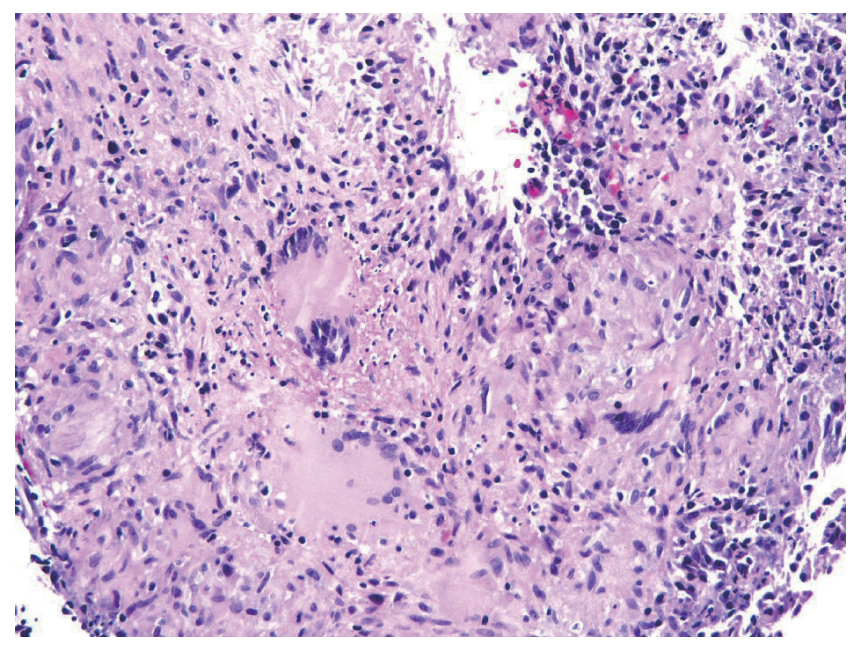

Figure 1. Biopsy from the colon revealed extensive large epithelioid granulomas with central necrosis. Acid-fast mycobacteria were identified by Ziehl-Neelsen stain in colon biopsies (picture not shown).

colitis in rheumatoid arthritis patients receiving infliximab is extremely low.

\section{4) Intestinal tuberculosis (TB)}

Although all anti-TNF biologics have been associated with reactivation of latent $\mathrm{TB}$, the risk of reactivation is higher with the monoclonal antibodies than with etanercept [10-12]. The incidence of TB was estimated to be 1,337 per 100,000 patient-years for infliximab, but only rare cases affected intestine [12]. One case of CD treated with infliximab developed pulmonary and intestinal tuberculosis after 20 months. This patient had been screened and was positive for latent TB but he had not been treated with anti-TB therapy before the initiation of infliximab [12]. A similar case of disseminated TB with colonic involvement developed after infliximab treatment for $\mathrm{CD}$ was reported in a patient even though they had completed a 9-month course of isoniazid for latent TB 2 months before the initiation of infliximab [13]. Despite anti-TB treatment, this patient died 8 months after the being diagnosed with disseminated TB [13]. An example of intestinal TB which developed after infliximab treatment for $\mathrm{CD}$ is illustrated in Figure 1.

\section{5) Cytomegaloviral (CMV) colitis}

In one review article of 369 patients with Behcet's disease treated with anti-TNF- $\alpha$ blockade therapy, one patient developed CMV colitis at 10 days after the third dose of infliximab which manifested as watery diarrhea and weight loss [14, 15]. Physical examination revealed epigastric tenderness on palpation and hyperactive bowel sounds. Laboratory studies at the time of admission revealed elevated $\mathrm{C}$ reactive protein, a positive CMV immunoglobulin (Ig) $\mathrm{G}$ but a negative IgM antibody, and negative stool studies for parasites, Clostridium difficile toxin, and enteric pathogens. Colonoscopy revealed dif- 
fuse erythematous and edematous mucosa and multiple ulcers throughout the colon, rectum, and terminal ileum. A colonic biopsy was interpreted as CMV colitis but the immunohistochemical illustrations depicted in the article are equivocal at best [15]. Cessation of infliximab and treatment with ganciclovir resulted in improvement of symptoms and colitis on repeat endoscopy. The patient had no recurrence of colitis at 30 months of follow-up. Although this report raises the possibility of CMV colitis associated with infliximab treatment, it did not address the possibility of infliximab-associated non-infectious colitis. The role of pathology expertise in the diagnosis of colitis in patients receiving anti-TNF therapies should be emphasized as no images from H\&E stained sections were presented in this report [15].

\section{Adalimumab}

\section{1) Ischemic colitis}

One case of ischemic colitis associated with adalimumab has been reported [16]. This documented case described a 60-yearold male with no concomitant medications or risk factors for ischemia. After an exploratory laparotomy revealed ischemic colitis, a right colectomy was performed and the patient recovered shortly after hospitalization. But one recent report suggests that the risk of ischemic colitis associated with adalimumab use in patients with rheumatoid arthritis appears to be extremely low as only 12 , including seven possible and five probable cases, were reported to be adalimumab-associated ischemic colitis, out of 155,372 cases who had indication of rheumatoid arthritis from the data submitted to US FDAAERS between January 2003 and June 2011[9]. The male to female ratio was 3:9 and the median age was 58.5 years (range 36 - 79) in this small cohort of patients with adalimumab-associated ischemic colitis. Eight cases were confirmed with colonoscopy with or without biopsy. One patient died, 10 patients recovered and one was without follow-up data.

\section{2) Apoptotic enteropathy}

Increased apoptosis in the gastrointestinal tract was reported in patients receiving adalimumab therapy for psoriasis [17]. These patients presented with abdominal pain and/or diarrhea and mucosal biopsies demonstrated a prominent increase in apoptotic bodies in the duodenum and terminal ileum [17].

\section{3) Intestinal TB}

The incidence of TB was estimated to be 792 per 100,000 patient-years for adalimumab, but most of these cases involved sites other than the gastrointestinal tract [12]. In the literature, one case of a patient with ankylosing spondylitis treated with adalimumab developed disseminated TB and mycobacteria were detected in feces after 31 months. This patient had been screened prior to the initiation of adalimumab and was found to be positive for latent TB [12].

4) Indolent T-cell lymphoproliferative disease of the gastrointestinal tract

One case of indolent T-cell lymphoproliferative disease of the gastrointestinal tract after treatment with adalimumab was reported in a patient with CD [18]. This patient had a 15-year history of CD which had been resistant to multiple medications including 5-aminosalycylic acid, corticosteroid enema, and azathioprine. The patient was treated with adalimumab for 7 months and a repeat biopsy from an endoscopically severely inflamed colon revealed active chronic colitis with multifocal dense infiltrates composed of small lymphocytes. These cells were $\mathrm{CD} 8+$, TIA+, TCR $\beta-\mathrm{F} 1+$ and showed TCRG and TCRB gene rearrangements. Adalimumab was discontinued and the monoclonal T-cell infiltrate subsequently regressed. However, a monoclonal T-cell infiltrate recurred within the gastrointestinal tract 2 years after the initial diagnosis of the T-cell lymphoproliferative disease.

\section{5) IBD}

One case of ulcerative pancolitis was reported in a patient with juvenile rheumatoid arthritis treated with etanercept with subsequent colitis flares following treatment with adalimumab and infliximab [19]. The patient's UC only healed after cessation of all anti-TNF agents including etanercept, adalimumab, and infliximab. This case suggested that, at least, some TNF blockade-associated colitis may be drug class specific, while other cases may be molecule specific and immune suppression dependent.

\section{Golimumab}

Golimumab is a TNF- $\alpha$ inhibitor that was approved in the United States in 2009 for treating adults with moderately to severely active rheumatoid arthritis, active psoriatic arthritis, or active ankylosing spondylitis [20]. Patients receiving golimumab for rheumatologic diseases have been reported to experience nausea and diarrhea with a frequency of 4.1-18.2\% and $4.3-7.9 \%$, respectively $[20,21]$, but none of the 304 patients receiving golimumab were reported to have had gastroenteritis [21].

\section{Certolizumab pegol}

\section{1) Ischemic colitis}

The risk of ischemic colitis associated with certolizumab pegol use in patients with rheumatoid arthritis is extremely low. From the data submitted to US FDA AERS between January 2003 and June 2011, thirty-five primary suspect reports of TNF- $\alpha$ inhibitors-associated ischemic colitis were identified 
from 155,372 cases who had indication of rheumatoid arthritis and only three of them, including two possible and one probable case, were reported to be certolizumab-associated. All three patients were female and had median age of 51 years (range 51 - 55) [9]. One case was confirmed with colonoscopy without biopsy. Two patients recovered and one was without follow-up data.

\section{Etanercept (Enbrel)}

\section{1) IBD}

Treatment with etanercept for rheumatological disease can exacerbate pre-existing UC $[6,22,23]$ or CD $[23,24]$. In addition, etanercept treatment for rheumatological diseases can induce the development of de novo IBD [17, 23, 25], UC [6] or CD $[19,26]$. In one recent study, the incidence of IBD in patients with juvenile idiopathic arthritis was 1.31 per 1,000 patient years, higher than in the general population [27]. Etanercept monotherapy, but not the combination of etanercept and methotrexate, was associated with an increased incidence of IBD at 5.33 per 1,000 patient years [27]. The IBD in this report included eight instances of CD and three cases of UC, all of which were histologically confirmed. Epithelioid granulomas were noted in three CD cases and one microgranuloma was noted in one case of ulcerative pancolitis [27]. Upper gastrointestinal tract involvement was reported in all three CD cases and included esophagitis in one patient, duodenitis in two patients, and gastritis in two patients. In this report, these patients had a mean exposure time of 1.71 (SD 1.29) years with a range of $0.34-5.03$ years before onset of IBD symptoms. Etanercept was discontinued in eight patients with a mean time of $5.5(0.0$ - 22.3) weeks after onset of IBD. No patients went into remission after discontinuation of only etanercept. All were treated for IBD using standard therapy and five of them also received other anti-TNF agents (adalimumab or infliximab) [27]. Ten patients had follow-up and IBD went into remission in five of them after anti-IBD treatment. A case of pancolitis occurring during etanercept treatment of rheumatoid arthritis was reported which also relapsed during the administration of further two TNF-alpha inhibitors, suggesting a class-specific toxicity [19]. While the mechanism underlying etanercept-induced IBD is not clear, the temporal association of onset IBD suggests that it may be associated with immunomodulation.

\section{2) Ischemic colitis}

The risk of ischemic colitis associated with etanercept use in patients with rheumatoid arthritis is extremely low. Out of 155,372 cases who had indication of rheumatoid arthritis using the data submitted to US FDA AERS between January 2003 and June 2011, only seven, including two possible and five probable cases, were reported to be etanercept-associated [9]. The male to female ratio was 1:6 and the median age was 64 years (range 58 - 80) in this small cohort of patients with etanercept-associated ischemic colitis. One case was confirmed with

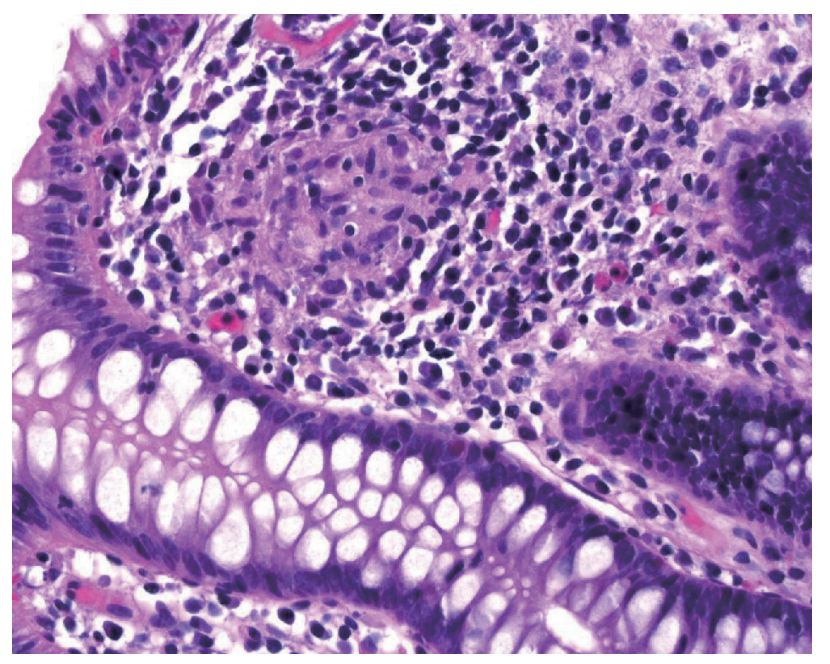

Figure 2. Colonic biopsy from one patient receiving etanercept for rheumatoid arthritis showed a non-caseating granuloma in the colonic mucosa without epithelial injury.

colonoscopy with biopsy. Six patients recovered and one died.

\section{3) Apoptotic enteropathy}

Increased apoptosis in the gastrointestinal tract including the colon was reported in patients receiving etanercept therapy for rheumatoid arthritis [17]. Patients presented with diarrhea and biopsies demonstrated a prominent increase in apoptotic bodies in the duodenum and mild increase in apoptotic bodies in the colon [17].

\section{4) Sarcoidosis-like lesions}

Sarcoidosis-like lesions have been increasingly reported during anti-TNF- $\alpha$ treatment for rheumatologic diseases and IBD. The lesion may affect the lungs, skin, or uvea. In one review, the authors identified 90 reported cases of sarcoidosis-like lesions, which developed during anti-TNF therapy [28]. In most cases, the anti-TNF drug involved was etanercept. The median age was 43 years and there was a predominance of female patients. The underlying disease was rheumatoid arthritis in most cases, followed by ankylosing spondylitis and psoriasiform arthritis. In six cases, the underlying disease was IBD. In 71 cases there was at least a partial resolution by discontinuation of the anti-TNF treatment with or without concurrent steroids. Re-initiation of anti-TNF therapy led to relapse in seven out of 20 cases. One case of sarcoidosis-like lesions was reported in the gastrointestinal tract including the stomach and the colon in a patient with ankylosing spondylitis [17]. In this case, the patient presented with protein losing enteropathy with active duodenitis, villous blunting, and patchy increased apoptotic bodies combined with active chronic antral and oxyntic nonH. pylori gastritis.

When encountering these types of granulomatous lesions, clinicians and pathologists should always exclude infectious 
agents. Additionally, although such sarcoidosis-like lesions affecting the gastrointestinal tract have not been reported in patients receiving anti-TNF- $\alpha$ treatment with underlying UC, this occurrence is potentially possible. The occurrence of granulomatous lesions, involving either intestinal or extra-intestinal sites, should not be taken as definitive evidence of CD in a case otherwise typical of UC in patients who received anti-TNF- $\alpha$ treatment. An example of an isolated non-caseating granuloma in the colonic mucosa without epithelial injury from a patient receiving etanercept for rheumatoid arthritis is illustrated in Figure 2.

Literatures on colitis-associated with anti-TNF $\alpha$ biologics is summarized in Table $3[6,8,9,12,13,15-19,26-28]$.

\section{Anti-interleukin 12/23 (anti-IL12/23) (ustekinumab)}

Ustekinumab is a human IgG $1 \kappa$ monoclonal antibody that binds to the common p40 subunit shared by IL12 and IL23, which inhibits their binding to the IL12R $\beta 1$ on the surface of T cells, natural killer (NK) cells, and antigen-presenting cells, preventing the subsequent receptor signaling and activation, and decreasing IL23-mediated interleukin 17 (IL17) production. Ustekinumab has been approved for psoriasis and psoriatic arthritis since 2009 [29] and was approved for moderately to severely active CD in 2016 [2]. Ustekinumab treatment within 12 weeks of surgery does not appear to increase the risk of postoperative complications above that of CD patients treated with anti-TNF medications. In addition, it was used to treat chronic granulomatous disease-associated colitis, common variable immunodeficiency-associated IBD, chronic refractory pouchitis, and paradoxical UC developed during adalimumab treatment of psoriasis [30-33].

\section{Anti-interleukin 17 (anti-IL17) (secukinumab)}

Secukinumab is a fully human, high-affinity, anti-IL17A monoclonal antibody. IL17A and its receptor are expressed in synovial tissue and mediate biological functions, leading to joint and enthesis inflammation, damage, and tissue remodeling. Secukinumab has been approved for psoriasis and psoriatic arthritis [1, 29]. CD was reported as a non-serious adverse effect in patients receiving secukinumab for their spondyloarthritis with an incidence rate of 8 per 1,000 patient-years of secukinumab exposure [34]. Similar results were reported in an additional study [35]. Exposure-adjusted incidence rates of $\mathrm{CD}$ and $\mathrm{UC}$ in subjects with plaque psoriasis receiving any dose of secukinumab in a cohort of 3,430 patients during the entire 52 weeks was low at 1.1 and 1.5 , respectively, per 1,000 subject-years of secukinumab exposure. The exposure-adjusted incidence rates of IBD in this patient population was low (3.3 per 1,000 subject-years), comparable to that of etanercept (3.4 per 1,000 subject-years) [35].

\section{Interleukin 1 (IL1) antagonists (anakinra and canakinum- ab)}

Anakinra is a recombinant, nonglycosylated human IL1 receptor antagonist which has been approved for treating moderately to severely active rheumatoid arthritis which has failed one or more disease-modifying antirheumatic drugs (DMARDs). Canakinumab is a recombinant human anti-IL1 $\beta$ monoclonal antibody which has been approved for treating active systemic juvenile idiopathic arthritis (sJIA). IBD seems to be a rare, but possible complication of sJIA and treatment with IL-1 antagonists might be a relevant factor for a switch in the clinical phenotype of the underlying inflammatory process [36]. In this report, three patients (out of 82) with sJIA developed CD (two cases) and UC (one case) $0.8-4.3$ years after the diagnosis of sJIA. All of them were treated with IL-1 antagonists (anakinra in two cases and canakinumab in one case). In one patient, abdominal pain and diarrhea developed after 11 months on anakinra and colonoscopy showed ileitis and discontinuous inflammation in the ascending colon with granulomatous inflammation on histology, features of CD. Anakinra was tapered and treatment with infliximab and methotrexate led to rapid remission. The other patient developed abdominal symptoms after 3 years on anakinra and methotrexate and colonoscopy 4 years after starting anakinra revealed severe inflammation in the descending colon with edematous and inflamed lamina propria and cryptitis. The patient was continued on low dose anakinra and treatment of mesalazine and azathioprine resulted in partial but not complete resolution. The third patient developed fatigue, diarrhea, and weight loss after 24 months on canakinumab and endoscopy revealed active colitis extending from the sigmoid to the cecum and inflamed terminal ileum. A duodenal biopsy demonstrated edematous and coarse villi with neutrophilic inflammation. Canakinumab was discontinued and treatment with budesonide and infliximab led to rapid remission in this patient.

\section{Anti-interleukin-6 receptor (anti-IL6-R) (tocilizumab)}

Tocilizumab is a humanized anti-IL6-R antibody and an established treatment for moderately to severely active rheumatoid arthritis which cannot be adequately controlled by conventional DMARDs. Despite its overall safety, concerns have been raised regarding diverticular perforation in patients receiving this drug. However, a recent systemic literature review revealed the risk of diverticular perforation may be slightly higher in patients treated with tocilizumab compared with conventional DMARDs or anti-TNF agents but lower than that for corticosteroids with rates of 1.9 per 1,000 patient years [37]. Although tocilizumab was reported to successfully treat patients with coexisting rheumatoid arthritis and UC [38] and patients with coexisting Takayasu arteritis complicated by UC [39], it may also cause exacerbation of UC in patients whose disease course is unresponsive to treatments including azathioprine, methotrexate, anti-TNF antibodies and tacrolimus [40]. In this one patient, biweekly intravenous tocilizumab for 12 weeks resulted in no clinical improvement and repeat endoscopic and histologic assessment demonstrated exacerbation of mucosal inflammation and ulcer formation.

\section{Anti-lymphocyte integrin $\alpha 4 \beta 7$ (vedolizumab, Entyvio)}

Vedolizumab is a humanized IgG1 monoclonal antibody that 

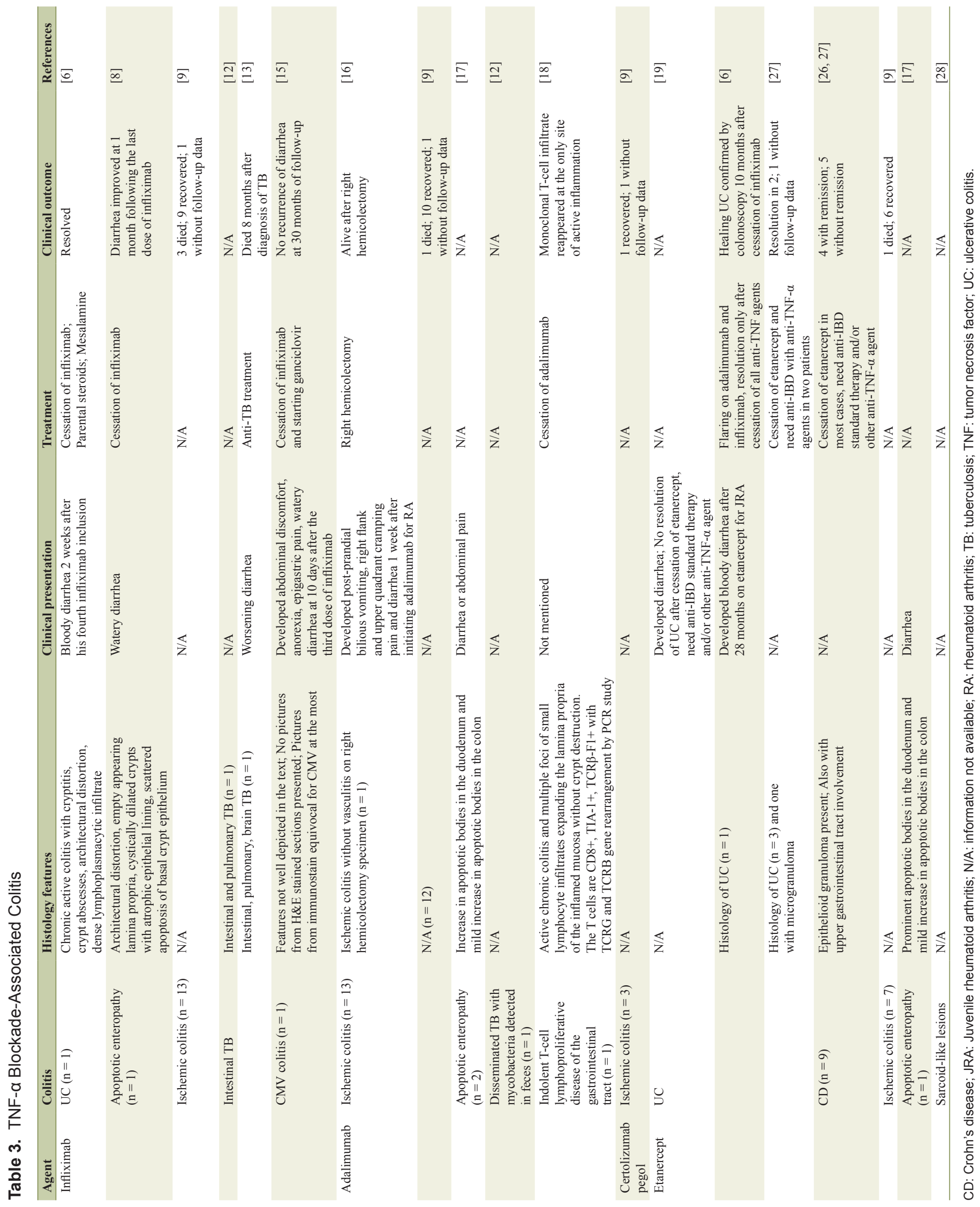
selectively blocks the lymphocyte integrin $\alpha 4 \beta 7$ and prevents its interaction with endothelial adhesion molecules and subsequent transmigration to the gastrointestinal tract. The drug was approved in 2014 for the induction and maintenance treatment of UC and moderate to severe CD that is refractory or intolerant to conventional therapy [41]. It has been found to be an effective first-line agent in treating moderate to severe UC [42]. Preoperative use of vedolizumab did not affect the risk of 30day postoperative complications in UC and CD [43]. One case of fatal ulcerative enteritis of the small bowel in a patient with UC treated with vedolizumab was reported [44]. This 64-yearold female patient had UC refractory to TNF inhibitors. The patient developed severe diarrhea and systemic inflammatory response syndrome (SIRS) 1 week after the second vedolizum$\mathrm{ab}$ infusion. Blood stream infections were ruled out. Endoscopy revealed extensive ulcerations of the duodenum covered by pseudomembranes. Biopsy from the duodenum confirmed subtotal destruction of small intestinal epithelia and colonization with Candida. Small mesenteric vessels were occluded by hyaline thrombi, likely as a result of SIRS. Concentrations of $\beta$-D-glucan were highly elevated, but antimycotic therapy for suspected invasive candidiasis did not result in any clinical benefit. Additional laboratory tests revealed elevated titers of antinuclear antibodies (ANA) at a titer of 1:800. Follow-up endoscopy revealed that the mucosa of the small intestine was almost completely replaced by fibrotic tissue with only scattered small islands of regenerating intestinal epithelium. Although an autoimmune phenomenon was suspected and immunosuppressive therapy was escalated, the patient eventually died from multi-organ failure 9 weeks after the second vedolizumab infusion. Autopsy revealed massive necrotic enterocolitis with bacterial colonization and complete loss of mucosa, particularly in the duodenum. The colon showed hemorrhage, ulcerations, and pseudopolyp formation consistent with chronically active colitis. Hyaline thrombi were detected in the small vessels throughout the gastrointestinal tract.

\section{Anti-Tumoral Agents}

\section{Anti-tumoral immune therapy}

The cytotoxic T-lymphocyte-associated antigen 4 (CTLA4 ) and programmed death 1 (PD-1) immune checkpoints are negative regulators of T-cell immune function [45]. Inhibition of these targets by antibodies, pembrolizumab (KEYTRUDA, anti-PD-1), nivolumab (OPDIVO, anti-PD-1), ipilimumab (antibody against CTLA-4), resulting in increased activation of the immune system, has been explored to treat melanoma, non-small cell lung cancer, and other malignancies [45-47].

\section{Anti-CTLA-4 antibody}

Ipilimumab is a CTLA-4 blocking monoclonal antibody. The use of this antibody has been shown to provide a significant survival benefit in metastatic melanoma patients [48, 49]. However, it is associated with gastrointestinal toxicity includ- ing diarrhea, colitis, and bowel perforation [49, 50]. Affected patients typically presented with diarrhea, either bloody or non-bloody, abdominal pain, and/or fever after ipilimumab infusion with a variable interval with 4 days to 8 weeks after the last dose or 7 - 13 weeks following initiation of therapy [48, 50-54]. Endoscopy in these patients showed loss of vascular pattern, erythema, friability, and granularity with or without ulcers $[48,49,54]$ and histology usually demonstrated expansion of lamina propria with mixed inflammatory infiltrates, focal cryptitis, crypt abscesses, rare apoptotic epithelial cells, and focal clustering of histiocytes centered on damaged glands $[48,49,54]$. In some cases, apoptosis of crypt epithelial cells can be prominent with intraepithelial lymphocytosis $[48,49]$. Rectal sparing may occur and the involvement pattern can be continuous or patchy [52]. In some cases, crypt distortion may occur [52]. Biopsies from the stomach, duodenum, and the terminal ileum may show similar features including mixed inflammatory infiltrates, intraepithelial lymphocytosis and villous blunting (in the small bowel) [48]. In rare cases, the inflammation may only affect the small bowel with complete sparing of the colonic mucosa [55]. Immunological studies on the biopsy material from patients with ipilimumab-associated colitis revealed abundance of plasma cells and CD4+ T cells in the lamina propria by immunohistochemistry as well as increased expression of interferon- $\gamma$ and IL17A mRNA by reverse transcriptase polymerase chain reaction (RT-PCR) [52]. Rare cases of late-onset IBD-like syndrome developing 3 years after ipilimumab therapy have been reported [56].

Management includes holding off or discontinuing ipilimumab, starting steroids as initial therapy followed by infliximab if there is no response to steroids, and/or surgical options for complications such as bowel perforation $[49,50]$. In patients with ipilimumab-associated colitis refractory to steroid or infliximab therapy, vedolizumab, an anti-integrin $\alpha 4 \beta 7$ antibody therapy may induce steroid-free remission [53]. Of course, in patients with checkpoint inhibitor-induced colitis refractory to corticosteroid treatment with or without immunomodulatory drugs such as infliximab, superimposed infection such as CMV should be ruled out either by detecting CMV antigen on the colonic biopsy or detecting CMV in the stool, blood, or by serology [51]. In some cases, a combination of the above methods should be used as immunohistochemistry for CMV antigen was only positive in two out of five cases [51].

\section{Anti-PD-1 antibodies}

Both pembrolizumab and nivolumab were initially approved for treatment of metastatic melanoma but the spectrum of malignancies for which these therapies can be given has greatly expanded to include non-small-cell lung cancer, gastroesophageal malignancies, and other tumors which demonstrate microsatellite instability. Gastrointestinal adverse effects are common after a treatment with checkpoint inhibitors. Patients under treatment with anti-PD-1 antibodies showed gastrointestinal adverse effects, such as diarrhea, in $6.0-16.0 \%$ with grade 3 - 4 adverse effects in up to $2.2 \%$ [47, 57-59]. The interval between the initiation of anti-PD-1 therapy and the onset of diarrhea is variable and ranges from 1 week to 19 weeks with a median in- 


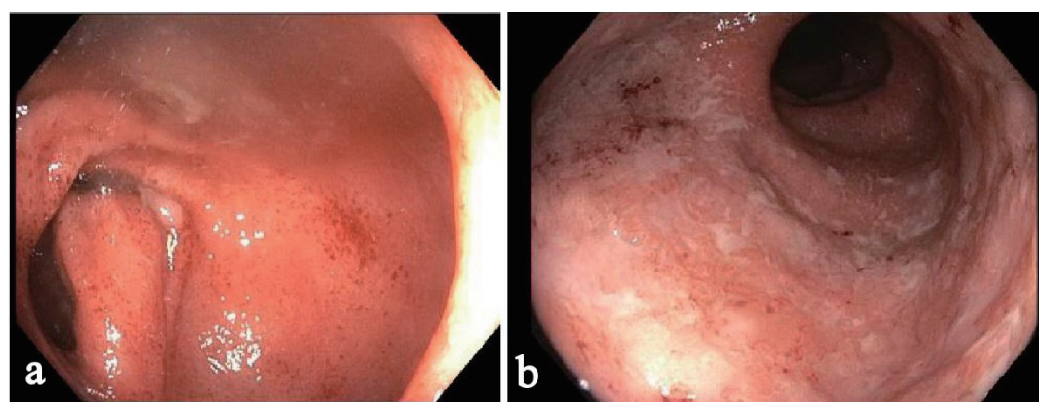

Figure 3. One example of anti-PD-1 monoclonal antibody-associated colitis by colonoscopy. There was a diffuse area of severely erythematous mucosa with friability and adherent exudates in the entire colon: (a) Sigmoid colon; (b) Rectum. The terminal ileum was normal.

terval of 3 months $[46,60]$. Information on anti-PD-1 therapyassociated colitis is scarce. The most common symptom is diarrhea $(89 \%)$ which is sometimes severe and/or bloody. There are endoscopic changes in the duodenum and stomach in $67 \%$ and $50 \%$ of patients. The terminal ileum is ulcerated in $40 \%$ of patients. There is mild colitis in $18 \%$, and marked changes including erosion and friability, either diffuse or patchy, in $47 \%$ of patients. The colonic mucosa is normal in $35 \%$ of patients [61].

The histology of anti-PD-1 therapy-associated colitis has been reported as lymphocytic colitis [46] in one case and collagenous colitis in two cases with increased plasmacytic and lymphocytic inflammation in the lamina propria and focal cryptitis $[60,61]$. One recent study reported more detailed histologic findings in anti-PD-1 therapy-associated gastroenterocolitis [61]. The histologic findings in the duodenal mucosa include lymphoplasmacytic expansion of the lamina propria and increased eosinophils in the lamina propria in $83 \%$ of patients and villous blunting and neutrophilic villitis in $67 \%$ of patients. Goblet cell attenuation or loss, prominent intraepithelial lymphocytosis, and increased apoptosis are seen in 50\%, 13\% and
$13 \%$ of patients, respectively. Histologic findings in the gastric mucosa are lymphoplasmacytic expansion of the lamina propria and intra-epithelial neutrophils in $67 \%$ of patients, gland abscesses in $50 \%$ of patients, crypt apoptosis in $13 \%$ of patients, and lamina propria eosinophils in $13 \%$ of patients. The histologic findings in the ileal mucosa include villous blunting, increased apoptosis, lamina propria expansion, and neutrophilic villitis, each seen in $60 \%$ of patients. Erosion/ulceration, lamina propria neutrophils, crypt abscesses, and increased eosinophils are each seen in $40 \%$ of cases. The colon is the most commonly biopsied organ. Lamina propria expansion and neutrophilic cryptitis are seen in the majority of cases. Crypt architectural distortion, neutrophilic crypt abscesses, and increased apoptosis are each seen in about $50 \%$ of cases. About $17.6 \%$ of cases show features resembling ischemic colitis with withered crypts, reactive epithelial changes, and a fibrotic-appearing lamina propria. In one case, the inflammatory process appeared to involve only the upper GI tract and small bowel, sparing the colon [61]. One example of anti-PD-1 therapy (nivolumab, OPDIVO)-associated colitis is illustrated in Figures 3 and 4.

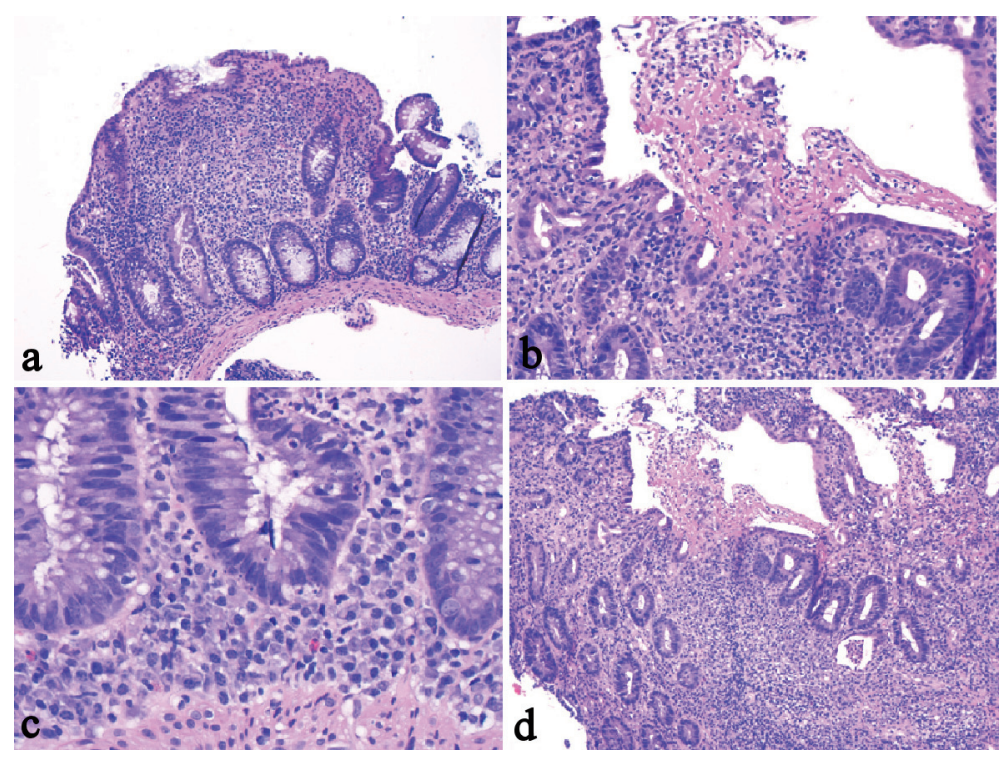

Figure 4. One example of anti-PD-1 monoclonal antibody-associated colitis. The biopsy from the colon revealed similar features including cryptitis, crypt abscess (a), mixed lymphoplasmacytic inflammation with erosion (b), cryptal apoptosis (c), and mild crypt distortion (d). The biopsy did not show surface intraepithelial lymphocytosis or granuloma. 
In patients with grade 2 and grade 3 adverse effects, checkpoint inhibitor treatment may need to be stopped and corticosteroids administered. In some cases, infliximab may be needed to treat the patients. Follow-up information on patients with anti-PD-1 antibody-associated colitis is limited. Gastrointestinal symptoms improved or resolved in $89 \%$ of patients, including $44 \%$ of patients who discontinued anti-PD- 1 therapy and 94\% who received additional medication (steroid, infliximab, fiber, and probiotics). Two patients had persistent diarrhea despite steroid therapy and loperamide, respectively [61].

\section{Anti-CD20 (rituximab)}

Rituximab is an anti-CD20 monoclonal antibody that has been used in the management of a form of B-cell targeted therapy in rheumatoid arthritis and low-grade lymphoma [62-64]. Rituximab therapy results in a depletion of systemic as well as intestinal B cell populations. Reported adverse effects included fever, chills, mucocutaneous reactions, fatal infusion reactions, and bowel perforation $[65,66]$. New onset UC and fulminant colitis $[64,67-70]$ and an exacerbation of previously documented colitis [71] have been reported. Also, a severe colitis that developed after rituximab therapy was reported to be related to an infectious torovirus agent [66]. Recently, one report described two cases of CD in two patients with small lymphocytic lymphoma and grade 2 follicular non-Hodgkin's lymphoma with an interval of 3 months and 22 months after completion of the treatment. One case involved the colon and the other affected the ileum with biopsies demonstrating neutrophilic inflammation, ulcer, and non-caseating granulomata [62] (Fig. 5). Rituximab therapy has also been reported to induce fulminant colitis in one patient with marginal zone B-cell lymphoma and lead to a subtotal colectomy with ileostomy [63]. Five years later, rituximab therapy for recurrent lymphoma in this patient led to diffuse severe colitis in her remaining colon, further suggesting a causal effect of rituximab in this patient's colitis. In some of the reports with follow-up biopsy, cessation of rituximab results in restoration of $\mathrm{CD} 20+\mathrm{B}$ lymphocytes and resolution of colitis [64]. These cases suggest that there is a protective effect of CD20+ lymphocytes in the gut and implicate that their depletion leads to the development and exacerbation of IBD. Clinical and histologic features of rituximab-associated colitis are summarized in Tables 4 and 5 [62-64, 66-70].

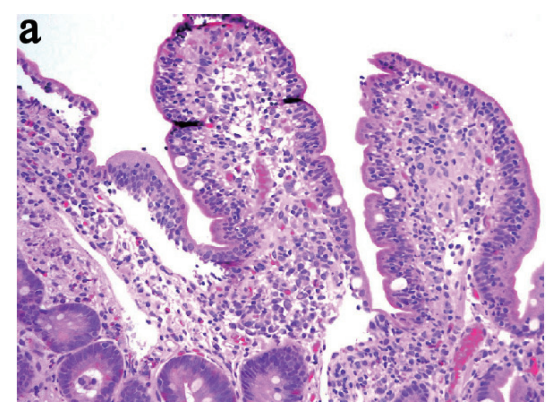

\section{Anti-vascular endothelial growth factor (bevacizumab)}

Bevacizumab, a monoclonal antibody against the vascular endothelial growth factor, has shown promise in the treatment of recurrent and metastatic colorectal cancer, metastatic nonsmall cell lung cancer, and other malignancies including ovarian cancer via a mechanism of inhibiting angiogenesis of the tumor. A number of cases have now been reported describing bowel perforation following bevacizumab treatment [72-76]. There also appears to be an especially increased risk of leakage at anastomotic suture sites following surgery for either UC or colorectal cancer [73]. In some cases, histological evidence of ischemia was noted [76].

\section{Conclusions}

This review examines and summarizes previously reported cases of colitis associated with several of the most recently available anti-inflammatory biologics and a few anti-tumoral immune therapies. With the availability of more anti-inflammatory biologics and anti-tumoral immunotherapies in the near future to treat human diseases, an increasing number of patients with colitis associated with these agents will be encountered by a variety of clinicians, including oncologists, generalists, gastroenterologists, and pathologists. Vigilance of and collaboration among the aforementioned physicians are essential for the early diagnosis and optimal management of such patients. Future research is also needed to determine predictive markers for developing anti-inflammatory biologics and immunotherapy-associated colitis, disease severity, response to corticosteroids and the need for anti-inflammatory biologics therapy.

\section{Disclosures}

None.

\section{Grant Support}

None.

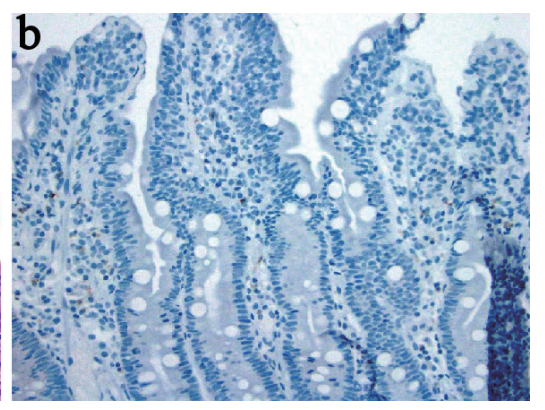

Figure 5. Biopsy from the terminal ileum from one patient treated with rituximab revealed mild surface intraepithelial lymphocytosis and a poorly formed non-caseating granuloma (a) ( H\&E stain), and a lack of CD20+ lymphocytes (b) (immunoperoxidase stain). 


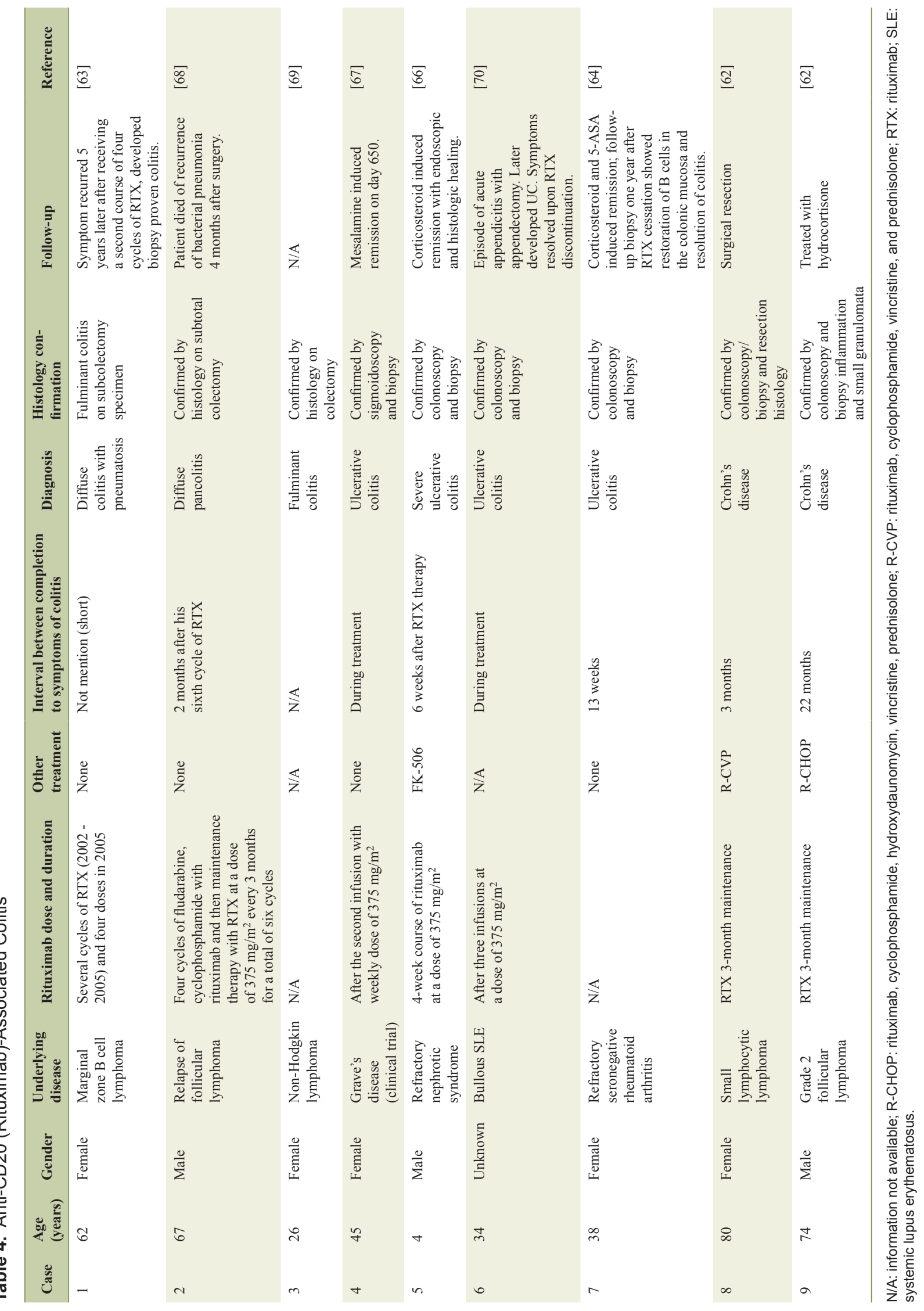




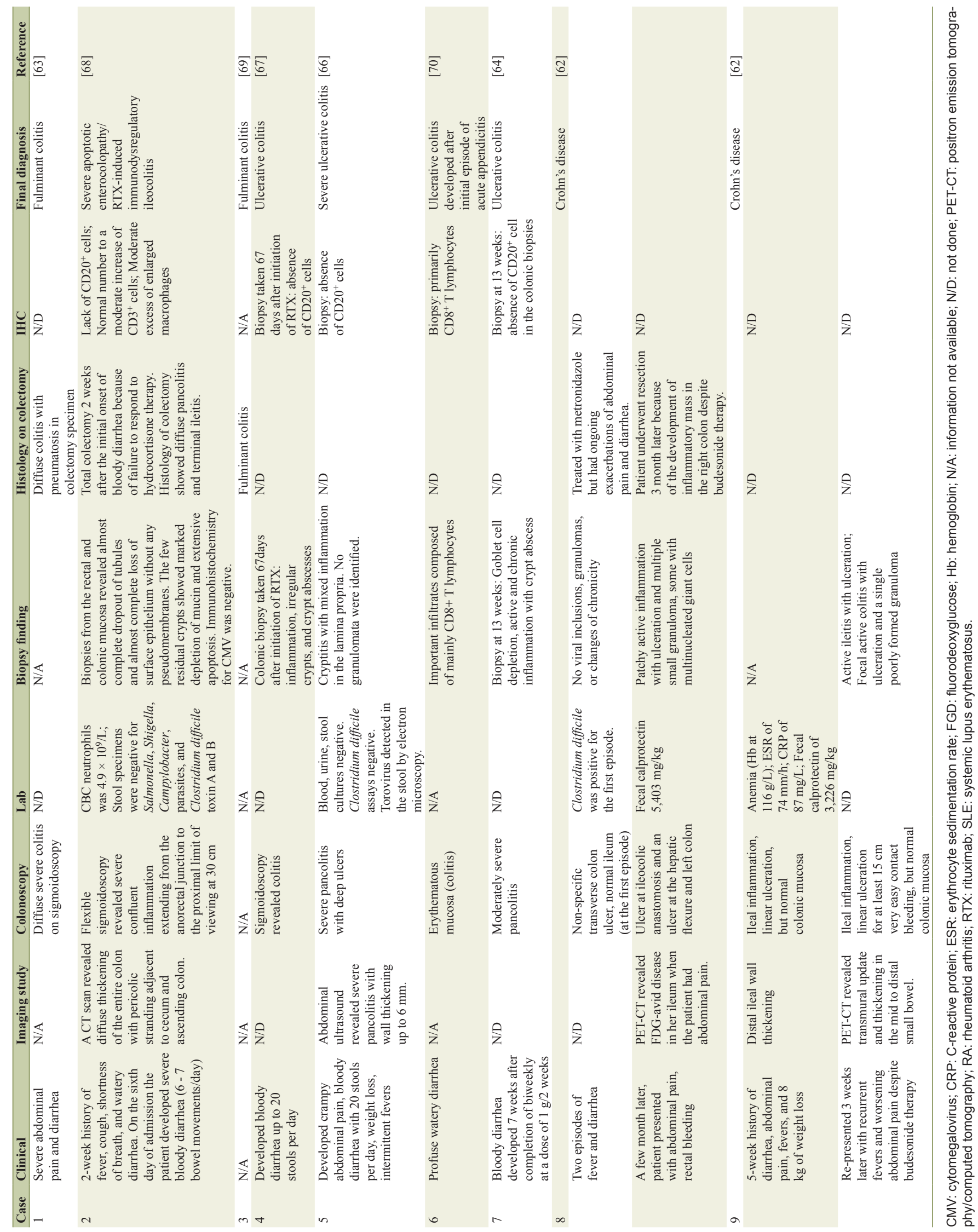




\section{References}

1. Baker KF, Isaacs JD. Novel therapies for immune-mediated inflammatory diseases: What can we learn from their use in rheumatoid arthritis, spondyloarthritis, systemic lupus erythematosus, psoriasis, Crohn's disease and ulcerative colitis? Ann Rheum Dis. 2018;77(2):175-187.

2. Lightner AL, McKenna NP, Tse CS, Hyman N, Smith R, Ovsepyan G, Fleshner P, et al. Postoperative outcomes in ustekinumab-treated patients undergoing abdominal operations for Crohn's disease. J Crohns Colitis. 2018;12(4):402-407.

3. Common Terminology Criteria for Adverse Events. CTCAE), v 4.0 [NCI/NIH web site]. May 29, 2009. Available at: evs.nci.nih.gov/ftp1/CTCAE/CTCAE_4.03_201006-14_QuickReference_8.5x11.pdf. Accessed January 1, 2015.

4. Taylor PC. Pharmacology of TNF blockade in rheumatoid arthritis and other chronic inflammatory diseases. Curr Opin Pharmacol. 2010;10(3):308-315.

5. Zavada J, Lunt M, Davies R, Low AS, Mercer LK, Galloway JB, Watson KD, et al. The risk of gastrointestinal perforations in patients with rheumatoid arthritis treated with anti-TNF therapy: results from the BSRBR-RA. Ann Rheum Dis. 2014;73(1):252-255.

6. Prescott K, Costner M, Cohen S, Kazi S. Tumor necrosis factor-alpha inhibitor associated ulcerative colitis. Am J Med Sci. 2007;333(3):137-139.

7. Horikoshi H, Takada K, Higuchi T, Yoshikawa T, Matsumoto M, Suzuki K. A case of ulcerative colitis complicating anti-tumor necrosis factor treatment for rheumatoid arthritis: successful treatment with leukocytapheresis. Int J Rheum Dis. 2013;16(1):107-109.

8. Soldini D, Gaspert A, Montani M, Reineke T, Rogler G, Odze R, Weber A. Apoptotic enteropathy caused by antimetabolites and TNF-alpha antagonists. J Clin Pathol. 2014;67(7):582-586.

9. Salk A, Stobaugh DJ, Deepak P, Ehrenpreis ED. Ischaemic colitis in rheumatoid arthritis patients receiving tumour necrosis factor-alpha inhibitors: an analysis of reports to the US FDA Adverse Event Reporting System. Drug Saf. 2013;36(5):329-334.

10. Dixon WG, Hyrich KL, Watson KD, Lunt M, Galloway J, Ustianowski A, Consortium BSRBRCC, et al. Drugspecific risk of tuberculosis in patients with rheumatoid arthritis treated with anti-TNF therapy: results from the British Society for Rheumatology Biologics Register (BSRBR). Ann Rheum Dis. 2010;69(3):522-528.

11. Tubach F, Salmon D, Ravaud P, Allanore Y, Goupille P, Breban M, Pallot-Prades B, et al. Risk of tuberculosis is higher with anti-tumor necrosis factor monoclonal antibody therapy than with soluble tumor necrosis factor receptor therapy: The three-year prospective French Research Axed on Tolerance of Biotherapies registry. Arthritis Rheum. 2009;60(7):1884-1894.

12. Abreu C, Magro F, Santos-Antunes J, Pilao A, RodriguesPinto E, Bernardes J, Bernardo A, et al. Tuberculosis in anti-TNF-alpha treated patients remains a problem in countries with an intermediate incidence: analysis of 25 patients matched with a control population. J Crohns Colitis. 2013;7(10):e486-492.

13. Wang MH, Liu X, Shen B. Disseminated tuberculosis in a patient taking anti-TNF therapy for Crohn's disease. ACG Case Rep J. 2015;3(1):45-48.

14. Arida A, Fragiadaki K, Giavri E, Sfikakis PP. Anti-TNF agents for Behcet's disease: analysis of published data on 369 patients. Semin Arthritis Rheum. 2011;41(1):6170.

15. Sari I, Birlik M, Gonen C, Akar S, Gurel D, Onen F, Akkoc N. Cytomegalovirus colitis in a patient with Behcet's disease receiving tumor necrosis factor alpha inhibitory treatment. World J Gastroenterol. 2008;14(18):29122914.

16. Gopalswamy S, Dindyal S, Arumugam P. A rare cause of ischemic colitis and review of literature. Internet J Gastroenterol. 2010;9(1):10.

17. Hutchings D, Voltaggio L. Histopathologic changes in the gastrointestinal tract during anti-tumoral necrosis- $\alpha$ therapy. Mod Pathol. 2017;30:176A [Abstract \#639].

18. Edison N, Belhanes-Peled H, Eitan Y, Guthmann Y, Yeremenko Y, Raffeld M, Elmalah I, et al. Indolent T-cell lymphoproliferative disease of the gastrointestinal tract after treatment with adalimumab in resistant Crohn's colitis. Hum Pathol. 2016;57:45-50.

19. Actis GC, Lagget M, Pellicano R, Rosina F. Pancolitis during etanercept treatment of rheumatoid arthritis relapsing on the administration of further two TNF-alpha inhibitors. Int J Colorectal Dis. 2012;27(4):547-548.

20. Boyce EG, Halilovic J, Stan-Ugbene O. Golimumab: Review of the efficacy and tolerability of a recently approved tumor necrosis factor-alpha inhibitor. Clin Ther. 2010;32(10):1681-1703.

21. Smolen JS, Kay J, Doyle MK, Landewe R, Matteson EL, Wollenhaupt J, Gaylis N, et al. Golimumab in patients with active rheumatoid arthritis after treatment with tumour necrosis factor alpha inhibitors (GO-AFTER study): a multicentre, randomised, double-blind, placebocontrolled, phase III trial. Lancet. 2009;374(9685):210221.

22. Davis JC, Jr., Van Der Heijde D, Braun J, Dougados M, Cush J, Clegg DO, Kivitz A, et al. Recombinant human tumor necrosis factor receptor (etanercept) for treating ankylosing spondylitis: a randomized, controlled trial. Arthritis Rheum. 2003;48(11):3230-3236.

23. O'Toole A, Lucci M, Korzenik J. Inflammatory bowel disease provoked by etanercept: report of 443 possible cases combined from an IBD Referral Center and the FDA. Dig Dis Sci. 2016;61(6):1772-1774.

24. Marzo-Ortega H, McGonagle D, O'Connor P, Emery P. Efficacy of etanercept for treatment of Crohn's related spondyloarthritis but not colitis. Ann Rheum Dis. 2003;62(1):74-76.

25. Verazza S, Davi S, Consolaro A, Bovis F, Insalaco A, Magni-Manzoni S, Nicolai R, et al. Disease status, reasons for discontinuation and adverse events in 1038 Italian children with juvenile idiopathic arthritis treated with etanercept. Pediatr Rheumatol Online J. 2016;14(1):68. 
26. Ruemmele FM, Prieur AM, Talbotec C, Goulet O, Schmitz J. Development of Crohn disease during antiTNF-alpha therapy in a child with juvenile idiopathic arthritis. J Pediatr Gastroenterol Nutr. 2004;39(2):203-206.

27. Barthel D, Ganser G, Kuester RM, Onken N, Minden K, Girschick HJ, Hospach A, et al. Inflammatory bowel disease in juvenile idiopathic arthritis patients treated with biologics. J Rheumatol. 2015;42(11):2160-2165.

28. Decock A, Van Assche G, Vermeire S, Wuyts W, Ferrante M. Sarcoidosis-like lesions: another paradoxical reaction to anti-TNF therapy? J Crohns Colitis. 2017;11(3):378383.

29. Song GG, Lee YH. Relative efficacy and safety of apremilast, secukinumab, and ustekinumab for the treatment of psoriatic arthritis. Z Rheumatol. 2017.

30. Butte MJ, Park KT, Lewis DB. Treatment of CGD-associated colitis with the IL-23 blocker ustekinumab. J Clin Immunol. 2016;36(7):619-620.

31. Ruiz de Morales JG, Munoz F, Hernando M. Successful treatment of common variable immunodeficiency-associated inflammatory bowel disease with ustekinumab. J Crohns Colitis. 2017;11(9):1154-1155.

32. Tran-Minh ML, Allez M, Gornet JM. Successful treatment with ustekinumab for chronic refractory pouchitis. J Crohns Colitis. 2017;11(9):1156.

33. Kolios AGA, Biedermann L, Weber A, Navarini AA, Meier J, Cozzio A, French LE. Paradoxical ulcerative colitis during adalimumab treatment of psoriasis resolved by switch to ustekinumab. Br J Dermatol. 2018;178(2):551555.

34. Braun J, Baraliakos X, Deodhar A, Baeten D, Sieper J, Emery P, Readie A, et al. Effect of secukinumab on clinical and radiographic outcomes in ankylosing spondylitis: 2-year results from the randomised phase III MEASURE 1 study. Ann Rheum Dis. 2017;76(6):1070-1077.

35. van de Kerkhof PC, Griffiths CE, Reich K, Leonardi CL, Blauvelt A, Tsai TF, Gong Y, et al. Secukinumab longterm safety experience: A pooled analysis of 10 phase II and III clinical studies in patients with moderate to severe plaque psoriasis. J Am Acad Dermatol. 2016;75(1):83-98 e84.

36. Hugle B, Speth F, Haas JP. Inflammatory bowel disease following anti-interleukin-1-treatment in systemic juvenile idiopathic arthritis. Pediatr Rheumatol Online J. 2017;15(1):16.

37. Gout T, Ostor AJ, Nisar MK. Lower gastrointestinal perforation in rheumatoid arthritis patients treated with conventional DMARDs or tocilizumab: a systematic literature review. Clin Rheumatol. 2011;30(11):1471-1474.

38. Szeto MC, Yalcin MD, Khan A, Piotrowicz A. Successful use of tocilizumab in a patient with coexisting rheumatoid arthritis and ulcerative colitis. Case Reports Immunol. 2016;2016:7562123.

39. Nishimoto N, Nakahara H, Yoshio-Hoshino N, Mima T. Successful treatment of a patient with Takayasu arteritis using a humanized anti-interleukin-6 receptor antibody. Arthritis Rheum. 2008;58(4):1197-1200.

40. Atreya R, Billmeier U, Rath T, Mudter J, Vieth M, Neumann H, Neurath MF. First case report of exacerbated ul- cerative colitis after anti-interleukin-6R salvage therapy. World J Gastroenterol. 2015;21(45):12963-12969.

41. Olmedo Martin RV, Amo Trillo V, Gonzalez Grande R, Jimenez Perez M. Efficacy and safety of vedolizumab as a treatment option for moderate to severe refractory ulcerative colitis in two patients after liver transplant due to primary sclerosing cholangitis. Rev Esp Enferm Dig. 2017;109(9):659-662.

42. Singh S, Fumery M, Sandborn WJ, Murad MH. Systematic review with network meta-analysis: first- and secondline pharmacotherapy for moderate-severe ulcerative colitis. Aliment Pharmacol Ther. 2018;47(2):162-175.

43. Yamada A, Komaki Y, Patel N, Komaki F, Aelvoet AS, Tran AL, Pekow J, et al. Risk of postoperative complications among inflammatory bowel disease patients treated preoperatively with vedolizumab. Am J Gastroenterol. 2017;112(9):1423-1429.

44. Monasterio C, Schmitt-Graff A, Pohl M, Truschel T, Warnatz K, Kreisel W, Thimme R, et al. Fatal ulcerative enteritis of the small intestine in a patient with ulcerative colitis treated with vedolizumab. Z Gastroenterol. 2017;55(10):1014-1020.

45. Buchbinder EI, Desai A. CTLA-4 and PD-1 pathways: similarities, differences, and implications of their inhibition. Am J Clin Oncol. 2016;39(1):98-106.

46. Hofmann L, Forschner A, Loquai C, Goldinger SM, Zimmer L, Ugurel S, Schmidgen MI, et al. Cutaneous, gastrointestinal, hepatic, endocrine, and renal side-effects of anti-PD-1 therapy. Eur J Cancer. 2016;60:190-209.

47. Larkin J, Chiarion-Sileni V, Gonzalez R, Grob JJ, Cowey CL, Lao CD, Schadendorf D, et al. Combined nivolumab and ipilimumab or monotherapy in untreated melanoma. N Engl J Med. 2015;373(1):23-34.

48. Oble DA, Mino-Kenudson M, Goldsmith J, Hodi FS, Seliem RM, Dranoff G, Mihm M, et al. Alpha-CTLA-4 $\mathrm{mAb}$-associated panenteritis: a histologic and immunohistochemical analysis. Am J Surg Pathol. 2008;32(8):11301137.

49. Klair JS, Girotra M, Hutchins LF, Caradine KD, Aduli F, Garcia-Saenz-de-Sicilia M. Ipilimumab-induced gastrointestinal toxicities: a management algorithm. Dig Dis Sci. 2016;61(7):2132-2139.

50. Marthey L, Mateus C, Mussini C, Nachury M, Nancey S, Grange F, Zallot C, et al. Cancer Immunotherapy with anti-CTLA-4 monoclonal antibodies induces an inflammatory bowel disease. J Crohns Colitis. 2016;10(4):395401.

51. Franklin C, Rooms I, Fiedler M, Reis H, Milsch L, Herz $\mathrm{S}$, Livingstone $\mathrm{E}$, et al. Cytomegalovirus reactivation in patients with refractory checkpoint inhibitor-induced colitis. Eur J Cancer. 2017;86:248-256.

52. Bamias G, Delladetsima I, Perdiki M, Siakavellas SI, Goukos D, Papatheodoridis GV, Daikos GL, et al. Immunological characteristics of colitis associated with anti-CTLA-4 antibody therapy. Cancer Invest. 2017;35(7):443-455.

53. Bergqvist V, Hertervig E, Gedeon P, Kopljar M, Griph H, Kinhult S, Carneiro A, et al. Vedolizumab treatment for immune checkpoint inhibitor-induced enterocolitis. Can- 
cer Immunol Immunother. 2017;66(5):581-592.

54. Verschuren EC, van den Eertwegh AJ, Wonders J, Slangen RM, van Delft F, van Bodegraven A, Neefjes-Borst A, et al. Clinical, endoscopic, and histologic characteristics of ipilimumab-associated colitis. Clin Gastroenterol Hepatol. 2016;14(6):836-842.

55. Messmer M, Upreti S, Tarabishy Y, Mazumder N, Chowdhury R, Yarchoan M, Holdhoff M. IpilimumabInduced Enteritis without Colitis: A New Challenge. Case Rep Oncol. 2016;9(3):705-713.

56. Akel R, Anouti B, Tfayli A. Late-onset inflammatory bowel disease-like syndrome after ipilimumab therapy: A Case Report. Case Rep Oncol. 2017;10(2):456-461.

57. Topalian SL, Hodi FS, Brahmer JR, Gettinger SN, Smith DC, McDermott DF, Powderly JD, et al. Safety, activity, and immune correlates of anti-PD-1 antibody in cancer. N Engl J Med. 2012;366(26):2443-2454.

58. Robert C, Long GV, Brady B, Dutriaux C, Maio M, Mortier L, Hassel JC, et al. Nivolumab in previously untreated melanoma without BRAF mutation. N Engl J Med. 2015;372(4):320-330.

59. Brahmer J, Reckamp KL, Baas P, Crino L, Eberhardt WE, Poddubskaya E, Antonia S, et al. Nivolumab versus docetaxel in advanced squamous-cell non-small-cell lung cancer. N Engl J Med. 2015;373(2):123-135.

60. Baroudjian B, Lourenco N, Pages C, Chami I, Maillet M, Bertheau P, Bagot M, et al. Anti-PD1-induced collagenous colitis in a melanoma patient. Melanoma Res. 2016;26(3):308-311.

61. Gonzalez RS, Salaria SN, Bohannon CD, Huber AR, Feely MM, Shi C. PD-1 inhibitor gastroenterocolitis: case series and appraisal of 'immunomodulatory gastroenterocolitis'. Histopathology. 2017;70(4):558-567.

62. Varma P, Falconer J, Aga A, Prince HM, Pianko S. Rituximab-induced Crohn's disease. Scand J Gastroenterol. 2017;52(5):606-608.

63. Lipka S, Katz S, Crawford JM. Fulminant colitis following rituximab therapy. Gastroenterol Hepatol (N Y). 2016;12(1):58-60.

64. Bhalme M, Hayes S, Norton A, Lal S, Chinoy H, Paine P. Rituximab-associated colitis. Inflamm Bowel Dis. 2013;19(3):E41-43.

65. Freeman HJ. Colitis associated with biological agents.
World J Gastroenterol. 2012;18(16):1871-1874.

66. Ardelean DS, Gonska T, Wires S, Cutz E, Griffiths A, Harvey E, Tse SM, et al. Severe ulcerative colitis after rituximab therapy. Pediatrics. 2010;126(1):e243-246.

67. El Fassi D, Nielsen CH, Kjeldsen J, Clemmensen O, Hegedus L. Ulcerative colitis following B lymphocyte depletion with rituximab in a patient with Graves' disease. Gut. 2008;57(5):714-715.

68. Blombery P, Prince HM, Levinson M, Pianko S, Maxwell E, Bhathal P. Rituximab-induced immunodysregulatory ileocolitis in a patient with follicular lymphoma. J Clin Oncol. 2011;29(5):e110-112.

69. Fernandez-Blanco I, Cara C, Perez M. De novo fulminant colitis after rituximab therapy on a non-Hodgkin lymphoma. Presented at United European Gastroenterology Week 2008; October 18-22, 2008; Vienna, Austria.

70. Sekkach Y, Hammi S, Elqatni M, Fatihi J, Badaoui M, Elomri N, Mekouar F, et al. [Ulcerative colitis: exceptional consequence after rituximab therapy]. Ann Pharm Fr. 2011;69(5):265-269.

71. Goetz M, Atreya R, Ghalibafian M, Galle PR, Neurath MF. Exacerbation of ulcerative colitis after rituximab salvage therapy. Inflamm Bowel Dis. 2007;13(11):13651368.

72. Gray J, Murren J, Sharma A, Kelley S, Detterbeck F, Bepler G. Perforated viscus in a patient with non-small cell lung cancer receiving bevacizumab. J Thorac Oncol. 2007;2(6):571-573.

73. Adenis A, Vanseymortier L, Foissey D, Colombel JF. Bevacizumab and postponed suture leakages after surgery for ulcerative colitis and rectal cancer. Gut. 2007;56(5):734.

74. August DA, Serrano D, Poplin E. "Spontaneous," delayed colon and rectal anastomotic complications associated with bevacizumab therapy. J Surg Oncol. 2008;97(2):180185.

75. Abbrederis K, Kremer M, Schuhmacher C. [Ischemic anastomotic bowel perforation during treatment with bevacizumab 10 months after surgery]. Chirurg. 2008;79(4):351-355.

76. Schellhaas E, Loddenkemper C, Schmittel A, Buhr HJ, Pohlen U. Bowel perforation in non-small cell lung cancer after bevacizumab therapy. Invest New Drugs. 2009;27(2):184-187. 